\title{
Toxicological and cytophysiological aspects of lanthanides action
}

\author{
Artur Pałasz and Piotr Czekaj ${ }^{\varpi}$
}

\section{Department of Histology and Embryology, Silesian Medical Academy, Katowice, Poland}

Received: 23 August, 2000; revised: 12 October, 2000; accepted: 10 November, 2000

Key words: lanthanides, gadolinium, calcium, metals, cytochrome P450.

Lanthanides, also called rare-earth elements, are an interesting group of $\mathbf{1 5}$ chemically active, mainly trivalent, f-electronic, silvery-white metals. In fact, lanthanides are not as rare as the name implies, except for promethium, a radioactive artificial element not found in nature. The mean concentrations of lanthanides in the earth's crust are comparable to those of life-important elements like iodine, cobalt and selenium. Many lanthanide compounds show particular magnetic, catalytic and optic properties, and that is why their technical applications are so extensive. Numerous industrial sources enable lanthanides to penetrate into the human body and therefore detailed toxicological studies of these metals are necessary. In the liver, gadolinium selectively inhibits secretion by Kupffer cells and it decreases cytochrome P450 activity in hepatocytes, thereby protecting liver cells against toxic products of xenobiotic biotransformation. Praseodymium ion $\left(\mathrm{Pr}^{3+}\right)$ produces the same protective effect in liver tissue cultures. Cytophysiological effects of lanthanides appear to result from the similarity of their cationic radii to the size of $\mathrm{Ca}^{2+}$ ions. Trivalent lanthanide ions, especially $\mathrm{La}^{3+}$ and $\mathrm{Gd}^{3+}$, block different calcium channels in human and animal cells. Lanthanides can affect numerous enzymes: $\mathrm{Dy}^{3+}$ and $\mathrm{La}^{3+}$ block $\mathrm{Ca}^{2+}$-ATPase and $\mathrm{Mg}^{2+}$-ATPase, while $\mathrm{Eu}^{3+}$ and $\mathrm{Tb}^{3+}$ inhibit calcineurin. In neurons, lanthanide ions regulate the transport and release of synaptic transmitters and block some membrane receptors, e.g. GABA and glutamate receptors. It is likely that lanthanides significantly and uniquely affect biochemical pathways, thus altering physiological processes in the tissues of humans and animals.

${ }^{凶}$ Corresponding author: Dr. Piotr Czekaj, II Department of Histology and Embryology, Medyków 18, 40-762 Katowice, Poland; e-mail: pcz@slam.katowice.pl

Abbreviations: lanthanum ions, $\mathrm{La}^{3+}$; cerium, $\mathrm{Ce}^{3+}$; praseodymium, $\mathrm{Pr}^{3+}$; neodymium, $\mathrm{Nd}^{3+}$; samarium, $\mathrm{Sm}^{3+}$; europium, $\mathrm{Eu}^{3+}$; gadolinium, $\mathrm{Gd}^{3+}$; terbium, $\mathrm{Tb}^{3+}$; dysprosium, $\mathrm{Dy}^{3+}$; holmium, $\mathrm{Ho}^{3+}$; erbium, $\mathrm{Er}^{3+}$; thulium, $\mathrm{Tm}^{3+}$; ytterbium, $\mathrm{Yb}^{3+}$; lutetium, $\mathrm{Lu}^{3+} ;$ cadmium, $\mathrm{Cd}^{2+}$; copper, $\mathrm{Cu}^{2+} ;$ zinc, $\mathrm{Zn}^{2+}$; manganese, $\mathrm{Mn}^{2+} ; 5$-HT, serotonine; ALT, alanine aminotransferase; AST, aspartate aminotransferase; GABA, $\gamma$-aminobutyrate; TNF, tumour necrosis factor. 
Lanthanides constitute an interesting group of 15 elements with similar physicochemical properties, which change periodically with the atomic number. Although lanthanides are termed rare-earth elements, they are not rare in nature because their levels in the earth's crust are often equal to or higher than those of some physiologically significant elements, such as iodine, cobalt and selenium. Cerium (68 p.p.m.) and lanthanum (32 p.p.m.) are the most common. Lutetium and thulium are the rarest (about 0.5 p.p.m.), while the concentrations of the remainder range from 1 do 9 p.p.m. Promethium is an artificial radioactive element with no stable isotopes (Brzyska, 1996).

Lanthanides are f-electronic, chemically active, silvery-white metals with atomic numbers from 51 to 71 . In nature, they never exist as pure elements, but only as sparsely distributed minerals, e.g., cerite, monazite and euxenite, or as admixtures in other ores. Lanthanides are definitely electropositive metals with the oxidation number of +3 . Only cerium, terbium and praseodymium with an oxidation number of +4 and samarium, europium and ytterbium with the oxidation number of +2 form stable compounds. The ionic radii of lanthanides range from $0.0848 \mathrm{~nm}(\mathrm{Lu})$ to $0.1034 \mathrm{~nm}(\mathrm{Ce})$, the values being relatively higher than those in other elements with the same oxidation number (Dzięgielewski, 1986; Brzyska 1996). The ionic radii of cerium, praseodymium, neodymium and gadolinium are similar to that of calcium $(0.104 \mathrm{~nm})$, the element that plays an essential role in many metabolic processes. This similarity determines physiologic effects of soluble lanthanide salts.

Lanthanide compounds frequently have magnetic, catalytic and optic properties and therefore they are widely used in industry. Such industrial sources of lanthanides are potentially hazardous to human health and therefore there is a need to more closely investigate the effects of these elements on tissue and organ functioning. In recent years, new experimental methods have been developed, thanks to which we have obtained new data on the role of lanthanides in the biochemical processes operating in cellular membranes, organelles and cytoplasm.

\section{TOXICOLOGICAL EFFECTS OF LANTHANIDES}

In the last twenty years new technologies have been introduced in metallurgical, optical and electronic industries, which increased the role of artificial lanthanide compounds with special physicochemical properties. At present, metallurgy utilizes about $37 \%$ of lanthanides and their compounds, mainly as misch metal composed of cerium (about $50 \%$ ), lanthanum (about 25\%), neodymium (about $18 \%$ ) and other lanthanides, which is used to remove oxygen and to enrich steel. Thirty three percent of lanthanides are used for catalytic converters, $29 \%$ in ceramic industry, and $1 \%$ in other industries. Pure lanthanide compounds are used in electronics and optoelectronics to produce luminophores (oxides of lanthanum, gadolinium, europium and terbium), lasers (e.g., halogens of neodymium, holmium and erbium), optical fibers, components of magnetic memories (e.g., gadolinium-gallium garnet, GGG), permanent magnets (alloys of samarium and neodymium) and high-temperature superconductors (Brzyska, 1996; RIC News, 1984-1995). Lanthanum chloride $\left(\mathrm{LaCl}_{3}\right)$ was added to chemical fertilizers (China Rare Earth Information, 1983-1995).

Since lanthanides and their compounds show a broad spectrum of industrial applications, there is an increased risk of their penetration into humans and animals, which may affect their metabolic processes. Toxicological studies of rats injected intravenously with chlorides of cerium, praseodymium, europium, dysprosium, ytterbium and lutetium have revealed that these compounds accumulate in the liver (over 78\%), bones and spleen. When given at doses of $18-20 \mathrm{mg} / \mathrm{kg}$, euro- 
pium and dysprosium show greater accumulation in the spleen and the lungs and increase calcium accumulation in the above-mentioned organs and the liver. Lanthanide ions are cleared from blood within 1 day, but they remain much longer in the organs. The percentages of europium and dysprosium in the liver reach the maximum between 8 and $24 \mathrm{~h}$ after administration and then they decrease gradually, while the concentration of praseodymium remains high (Nakamura et al., 1997).

In rat organs, cerium and praseodymium produce hepatotoxic effects, such as liver steatosis, jaundice, and increased serum alanine aminotransferase (ALT) and aspartate aminotransferase (AST) levels, which are maximal 3 days after treatment (Nakamura et al., 1997). The toxic effects of gadolinium include mineral deposits in capillaries (mainly in lungs and kidneys), necrosis in liver and spleen, mineralization of gastric mucosa without necrosis, thrombocytopenia and prolonged prothrombin time. Ultrastructurally, Kupffer cells and hepatocytes show deposits of gadolinium and calcium phosphates (Spencer et al., 1997). Cerium is thought to accumulate in animal organs in magnesium deficiency, which may be a cause of cardiac fibrosis leading to cardiomyopathy (Eapen et al., 1996). In humans exposed to asbestos and dusts containing lanthanide compounds, the lung macrophages and elastic fibers within the pulmonary tract contained cerium compounds (Pairon et al., 1995), suggesting that this element accumulates in the lung and may be involved in the pathogenesis of pulmonary diseases.

Gadolinium in the form of $\mathrm{GdCl}_{3}$ is a selective inhibitor of phagocytosis in liver macrophages (Kupffer cells) and at the same time it contributes to the selective elimination of these cells because it blocks the K-type $\mathrm{Ca}^{2+}$-channels by competing with membrane calcium. This competition is due to the fact that the cristal radius of gadolinium is similar to that of calcium, while the valency of the former is higher (Klein et al., 1994; Roland et al.,
1999). $\mathrm{GdCl}_{3}$ moderately alters microvascular perfusion in rat liver (Rüttinger et al., 1996) and reversibly decreases $\mathrm{O}_{2}$ consumption by lowering the levels of mitochondrial cytochromes $c_{1}$ and $c$ (Ferreira et al., 1998). Moreover, gadolinium increases the expression of hepatic cytokines and several cytokine-regulated transcription factors, such as c-JUN, $\mathrm{C} / \mathrm{EBP}-\beta$, and C/EBP- $\delta$ (Decker, 1990; Rai et al., 1996).

Gadolinium ions, via blocking calcium channels, inhibit hepatic microsomal epoxide hydrolase and glutathione $S$-transferases and shift the dose-inhibitory response curves for protein kinase $\mathrm{C}$ inhibitors, such as acriflavine, proflavine and safranine $\mathrm{O}$, which are also known as suppressors of drug metabolizing enzymes (Kim et al., 1998). Gadolinium given at a dose of $7-10 \mathrm{mg} \mathrm{GdCl}_{3} / \mathrm{kg}$ decreases the total cytochrome $\mathrm{P} 450$ content of hepatocytic microsomes and cytochrome P450-dependent monooxygenase activities and contributes to the reduction of liver injury caused by superoxides and toxic products of biotransformation of such xenobiotics as acetaminophen, carbon tetrachloride, 1,2-dichlorobenzene, and ethanol (Olynyk et al., 1998; Michael et al., 1999; Neyrinck et al., 1999; Yokoyama et al., 1999). This suggests that the protective effect of gadolinium on hepatocytes is cytochrome P450 dependent (Fig. 1). The possible mechanisms by which gadolinium ions inhibit cytochrome $\mathrm{P} 450$ include stimulation of TNF and IL-6 relase from Kupffer cells (these two cytokines inhibit cytochrome P450) and inhibition of the release of cytokines (e.g., IL-4) that maintain the constitutive expression of cytochrome P450 (Abdel-Razzak et al., 1993; Rai et al., 1996; Badger et al., 1997). Since $\mathrm{Gd}^{3+}$ can penetrate into hepatocytes and also protect isolated hepatocytes, it is likely that their protective effect is mediated by one of the mechanisms by which heavy metals affect cytochrome $\mathrm{P} 450$ in target cells, e.g., inhibition of heme biosynthesis, stimulation of heme catabolism via inducing heme oxidase (e.g., lead, nickel, cobalt, 
cadmium and tin), and direct binding to cytochrome $\mathrm{P} 450$ protein (e.g., tin) (Escalante et al., 1993; Badger et al., 1997). Interestingly, some ions of heavy metals selectively inhibit individual isoforms of cytochrome $\mathrm{P} 450$ (e.g., lead inhibits CYP1A2) and induce TNF $\alpha$ ex-

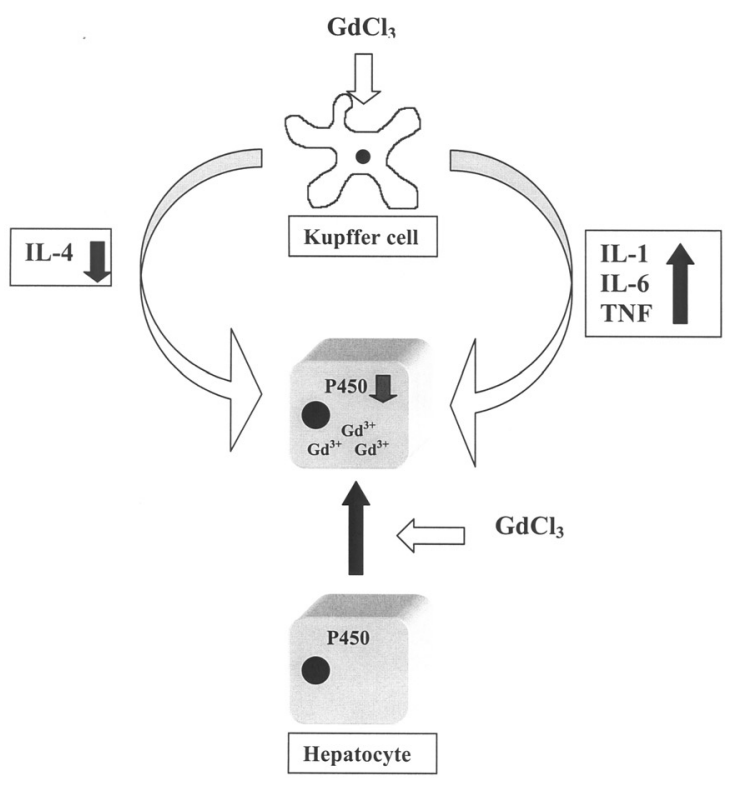

Figure 1. Possible pathways of hepatic cytochrome $\mathbf{P 4 5 0}$ activity inhibition by $\mathrm{GdCl}_{3}$.

Gd-dependent increase in the production of P450-inhibiting cytokines (Il-6, IL-1, TNF), Gd-dependent decrease in the production of $\mathrm{P} 450$-stimulating cytokine IL-4 in Kupffer cells, and penetration of $\mathrm{Gd}^{3+}$ into the hepatocyte reduce $\mathrm{P} 450$ expression and its monooxygenase activities (based on Badger et al., 1997; modified).

pression (Degawa et al., 1995). Direct binding of gadolinium to cytochrome P450 seems improbable because it does not alter the spectral profile of cytochrome P450. It is supposed that after entering the cell, gadolinium is activated by enzymes that may be not present in the microsomes.

Other lanthanides also have a protective effect on liver cells. For example, praseodymium protects them against phalloidin in vivo, which was explained by the finding that $\mathrm{Pr}^{3+}$ stimulated cell proliferation. Hepatocytes isolated from animals treated with $\mathrm{Pr}^{3+}$ were also less sensitive to phalloidin (Barriault et $a l .$, 1995). The mitogenic effect of lanthanides may result from the action of liver TNF, which is known to promote liver regeneration after partial hepatectomy (Rai et al., 1996). In addition, it has been found that not only liver macrophages but also liver endothelial and biliary epithelial cells are a source of TNF. This finding may explain the paradoxical gadolinium-induced increase in liver TNF despite the elimination of zone 1 Kupffer cells by lanthanides and normal levels of circulating TNF. On the other hand, the blockade of Kupffer cells by $\mathrm{Gd}^{3+}$, which results in the inhibition of their function, prevents the proliferation and maturation of oval cells, but not the proliferation of bile ductules and myofibroblast transformation after bile duct ligation (Olynyk et al., 1998). Further study is required to find out whether this stage of liver regeneration is controlled by Kupffer cells or whether $\mathrm{Gd}^{3+}$ directly affects the oval cells.

To sum up, the unexplained mechanism of cytoprotecive action of lanthanides (together with cytochrome P450) in the liver is clearly complex in its nature and involves intercellular interactions. However, the net toxic effect may be a combination of the hepatotoxic action of the active metabolite generated by the microsomal biotransformation of a xenobiotic and the effects of lanthanide ions i.e. selective blockade of Kupffer cells via calcium channels, changes in hepatic microvascular perfusion, increased TNF and other cytokines levels, direct action of lanthanide ions on different liver cell types, and on the rate of repair processes. Since the above-mentioned adverse effects of $\mathrm{GdCl}_{3}$ on the liver were severe (usually at $10 \mathrm{mg} / \mathrm{kg}$ ) in studies concerning the effects of lanthanides used as agents modulating the function of hepatic cells, it is essential to determine the minimum effective dose of $\mathrm{GdCl}_{3}$ that will have a cytoprotective effect on liver cells. 


\section{CYTOPHYSIOLOGICAL EFFECTS OF LANTHANIDES}

Lanthanide ions have been shown to affect the function of ionotropic receptors (i.e. ligand-gated ionic channels) and R7G metabotropic receptors. $\mathrm{La}^{3+}$ and $\mathrm{Gd}^{3+}$ competitively block many types of voltage-gated calcium channels in cells from many tissues and organs (Wadkins et al., 1998). Gd ${ }^{3+}$ blocks stretch-sensitive ionic channels (SAC) in the sarcolemma of skeletal muscle fibers (Coirault et al., 1999).

The physiological effects of lanthanides observed at the cellular level result largely from the fact that the sizes of their ionic radii are similar to that of calcium, which enables them to compete with calcium ions. A study of thyroid $\mathrm{C}$ cells has shown that lanthanide ions are antagonists of type $\mathrm{T}$ calcium channels, which are a subtype of voltage-gated channels (Tsien et al., 1988; Mlinar \& Enyeart, 1993). The ions with short radii are the strongest inhibitors. In the larger ions, the channel-blocking potential varies in inverse proportion to the ionic radius. Based on studies of ionic concentrations that block the type $\mathrm{T}$ calcium channel (0.1-1.0 $\mu \mathrm{M})$, the potencies of lanthanides to block this channel have been arranged in the following order: $\mathrm{Ho}^{3+}>\mathrm{Yb}^{3+} \geq$ $\mathrm{Er}^{3+}>\mathrm{Gd}^{3+}>\mathrm{Nd}^{3+}>\mathrm{Ce}^{3+}>\mathrm{La}^{3+}$. An increase in intracellular $\mathrm{Ca}^{2+}$ levels diminishes the blocking potency of $\mathrm{Ho}^{3+}$, indicating competitive antagonism between $\mathrm{Ca}^{2+}$ and $\mathrm{Ho}^{3+}$. The mechanism of blockade of voltage-gated type $\mathrm{T}$ calcium channels probably involves closure of the channel pore by an antagonist coupled with an appropriate metal-binding active site that is not influenced by the electric field of the membrane (Mlinar \& Enyeart, 1993).

$\mathrm{Gd}^{3+}$ ions are also able to inhibit vasopressin-stimulated inflows of $\mathrm{Ca}^{2+}$ and $\mathrm{Mn}^{2+}$ into the hepatocyte's cytoplasm. There are probably two mechanisms that regulate these $\mathrm{Ca}^{2+}$ and $\mathrm{Mn}^{2+}$ inflows, one is lanthanide-dependent and the other is not. The influence of $\mathrm{Tb}^{3+}, \mathrm{Gd}^{3+}, \mathrm{Eu}^{3+}$ and $\mathrm{Nd}^{3+}$ on the lanthanide- dependent calcium channel has been studied. All these ions inhibited the vasopressin-stimulated inflows of $\mathrm{Ca}^{2+}$ and $\mathrm{Mn}^{2+}$ into the cytoplasm, but not in the absence of an agonist or when $\mathrm{Ca}^{2+}$ was released from the intracellular stores. Among the lanthanides studied $\mathrm{Gd}^{3+}$ and $\mathrm{Eu}^{3+}$ show the lowest values of the dissociation constant. The dissociation constant for $\mathrm{Gd}^{3+}$ increases with extracellular $\mathrm{Ca}^{2+}$ levels, suggesting that $\mathrm{Gd}^{3+}$ ions competitively inhibit calcium binding. In the absence of lanthanide ions, the vasopressin-stimulated $\mathrm{Mn}^{2+}$ inflow into hepatocytes decreases at the moment of cell membrane depolarization caused by increased extracellular $\mathrm{K}^{+}$levels. It is likely that the lanthanide- and vasopressinsensitive calcium channel contains a carboxylic-rich domain capable of binding $\mathrm{Ca}^{2+}, \mathrm{Mn}^{2+}$ and lanthanide ions (Fernando \& Barritt, 1995).

Gadolinium ions and, to a lesser degree, lanthanum ions inhibit selective mechanosensoric calcium channels in plants. $\mathrm{Gd}^{3+}$ shows a weak inhibitory effect at an extracellular concentration of $0.5 \mu \mathrm{mol}$, while at 1-2 $\mu \mathrm{mol}$ the inhibition is complete. $\mathrm{La}^{3+}$ blocks these channels at much higher concentrations compared with $\mathrm{Gd}^{3+}$ (Ding \& Picard, 1993).

Lanthanides inhibit $\mathrm{Ca}^{2+}$-ATPase in the sarcoplasmic reticulum of skeletal muscle fibers. It is suggested that $\mathrm{Dy}^{3+}$ inhibits this enzyme much more than other lanthanide ions (Van der Laarse et al., 1995). $\mathrm{La}^{3+}$ and $\mathrm{Tb}^{3+}$ trigger phosphorylation of $\mathrm{Ca}^{2+}$-ATPase and increase the half-life of the phosphorylated enzyme (Asturias et al., 1994). Lanthanum ions can inhibit $\mathrm{Mg}^{2+}$-ATPases and choline esterases and activate kinase C (Wadkins et al., 1998). $\mathrm{Eu}^{3+}$ is able to replace $\mathrm{Ca}^{2+}$ bound to calcineurin $\left(\mathrm{Ca}^{2+} /\right.$ calmodulin- dependent phosphatase). The binding of $\mathrm{Tb}^{3+}$ by calcineurin is slightly weaker. The C-terminal domain of calcineurin shows higher affinity for lanthanide ions (Burroughs et al., 1994).

In neurons, $\mathrm{La}^{3+}, \mathrm{Gd}^{3+}$ and $\mathrm{Lu}^{3+}$ at a concentration of $100 \mathrm{nM}-100 \mu \mathrm{M}$ can directly trig- 
ger the release of neurotransmitters (Vaccari et al., 1999) or $\left(\mathrm{La}^{3+}\right)$ block the $\mathrm{Ca}^{2+}$-dependent mechanism of this release (Przywara et al., 1992; Vaccari et al., 1999). $\mathrm{La}^{3+}$ interacts with the monoamine- and $\mathrm{Na}^{+}$-binding sites of neurons, thus inhibiting the binding of $\mathrm{Ca}^{2+}$ to the synaptosome membrane (Basu et al., 1982) and the functioning of membrane proteins that transport such neuromediators as epinephrine, serotonin (5-HT) and dopamine. However, lanthanides ions cannot replace $\mathrm{Na}^{+}$in the active sites. $\mathrm{Eu}^{3+}$ inhibits the cellular uptake of norepinephrine (Bryan-Lluka \& Bonish, 1997).

Lanthanide ions visibly affect $\mathrm{GABA}_{\mathrm{A}}$ receptors in both the central and peripheral nervous systems. Lanthanum binds to an active site of the GABA receptor-chloride channel, the site being different from that binding GABA, pictotoxin, barbiturates, benzodiazepines, $\mathrm{Cu}^{2+}$ and $\mathrm{Zn}^{2+}$. As a result, the affinity of the receptor for GABA increases. Lanthanides with higher atomic numbers have stimulatory effect, the potency of which increases with the atomic number. A study of the functioning of an individual channel has shown that $\mathrm{Tb}^{3+}$ prolong the opening time and shorten the closing time of the ionic channel (Narahashi et al., 1994). It is likely that $\mathrm{Tb}^{3+}$ binds to the allosteric active site of the GABA receptor-ionic channel complex, thus prolonging the mean opening time of the channel by increasing the affinity of the ligand for the binding site (Ma et al., 1994). Many lanthanides enhance GABA response (prolongation of the opening time of the chloride channel) and this effect varies in inverse proportion to the radius of the hydrated ion. As a result, the opening time of the channel and the amplitude of the voltage induced by lanthanide ions decreases with the atomic number as follows: $\mathrm{Lu}^{3+}>\mathrm{Er}^{3+}>\mathrm{Tb}^{3+}>\mathrm{Eu}^{3+}>$ $\mathrm{Nd}^{3+}>\mathrm{Ce}^{3+}>\mathrm{La}^{3+}$ (Ma et al., 1993). On the other hand, an in vitro study (with voltage clamps) has shown no correlation between the size of the lanthanide ion and the magnitude of the potential evoked by trivalent lanthanum, cerium, neodymium, gadolinium, terbium, erbium and ytterbium ions acting on the $\mathrm{GABA}_{\mathrm{A}}$ receptor of cholinergic neurons in rats (Kumamoto \& Murata, 1996). $\mathrm{La}^{3^{+}}$and $\mathrm{Gd}^{3+}(2-4 \mu \mathrm{M})$ are antagonists of the kainic type of glutaminergic receptors probably because they directly interact with the ligand (Huettner et al., 1998).

This review presents data on the effects of lanthanides on membrane transport of ions, the functioning of receptors and microsome electron transport chains, especially of cytochrome $\mathrm{P} 450$, which is the terminal oxidase in these systems. It is likely that lanthanide ions significantly and uniquely affect biochemical pathways, thus altering physiological processes in the cells of humans, animals and plants. The mechanisms mediating the effects of lanthanides on cellular functioning are still unclear and require further study.

\section{R E F E R E N C E S}

Abdel-Razzak, Z., Loyer, P., Fautrel, A., Gautier, J., Corcos, L., Turlin, B., Beanne, P. \& Guillouzo, A. (1993) Cytokines down-regulate of major cytochrome P450-enzymes in adult human hepatocytes in primary culture. Mol. Pharm. 44, 707-715.

Asturias, F., Fischetti, R. \& Blasie, J. (1994) Changes in the profile structure of the sarcoplasmic reticulum membrane induced by phosphorylation of the $\mathrm{Ca}^{2+}$ ATPase enzyme in the presence of terbium: A time resolved x-ray diffraction study. Biophys. J. 66, 1653-1664.

Badger, D., Kuester, R., Sauer, J. \& Sipes, I. (1997) Gadolinium chloride reduces cytochrome P450: Relevance to chemical-induced hepatotoxicity. Toxicology 121, 143-153.

Barriault, C., Audet, M., Yousef, I. \& Tuchweber, B. (1995) Effects of agents which modify reticuloendothelial system function on acute phalloidin-induced lethality and hepatotoxicity in mice. Toxicol. Appl. Pharmacol. 131, 206-215. 
Basu, A., Chakrabarty, K. \& Chatterje, H. (1982) Neurotoxicity of lanthanum chloride in newborn chicks. Toxicol. Lett. 14, 21-25.

Bryan-Lluka, L. \& Bonish, H. (1997) Lanthanides inhibit human noradrenaline, 5-hydroxytryptamine and dopamine transporters. Naunyn. Schmiedebergs. Arch. Pharmacol. 355, 699-706.

Brzyska, W. (1996) Lantanowce i aktynowce, pp. 40-41, Wydawnictwa Naukowo-Techniczne, Warszawa (in Polish).

Burroughs, S., Horrocks, W., Jr., Ren, H. \& Klee, C. (1994) Characterization of the lanthanide ion-binding properties of calcineurin-B using laser-induced luminescence spectroscopy. Biochemistry 33, 10428-10436.

China Rare Earth Information (1983-1995) Baotou RE Research Institute. Baotou, Inner Mongolia.

Coirault, C., Sauviat, M.-P., Chemla, D., Pourny, J.-C. \& Lecarpentier, Y. (1999) The effects of gadolinium, a stretch-sensitive channel blocker, on diaphragm muscle. Eur. Respir. J. 14, 1297-1303.

Decker, K. (1990) Biologically active products of stimulated liver macrophages (KC). Eur. J. Biochem. 192, 245-261.

Degawa, M., Arai, H., Kubota, M. \& Hashimoto, Y. (1995) Ionic lead, but not other ionic metals $\left(\mathrm{Ni}^{2+}, \mathrm{Co}^{2+}\right.$ and $\left.\mathrm{Cd}^{2+}\right)$, suppresses 2-methoxy4-aminoazobenzene-mediated cytochrome P450IA2 (CYP1A2) induction in rat liver. Biol. Pharm. Bull. 18, 1215-1218.

Ding, J.P. \& Pickard, B.G. (1993) Mechanosensory calcium-selective cation channels in epidermal cells. Plant J. 3, 83-110.

Dzięgielewski, J. (1986) Chemia nieorganiczna, tom III; Chemia metali grup pobocznych, pp. 238-239, Wydawnictwo Uniwersytetu Ślaskiego, Katowice (in Polish).

Eapen, J., Kartha, C., Rathinam, K. \& Valiathan, M. (1996) Levels of cerium in the tissues of rats fed a magnesium-restricted and cerium-adulterated diet. Bull. Environ. Contam. Toxicol. 56, 178-182.
Escalante, B., Erlij, D., Falck, J. \& McGiff, J. (1993) Cytochrome P450-dependent arachidonate metabolites affect renal transport in the rabbit. J. Cardiovasc. Pharm. 22 (Suppl. 2), S106-S108.

Fernando, K. \& Barritt, G. (1995) Characterisation of the divalent cation channels of the hepatocyte plasm membrane receptor-activated $\mathrm{Ca}^{2+}$ inflow system using lanthanide ions. Biochim. Biophys. Acta. 1268, 97-106.

Ferreira, J., Tapia, G. \& Videla, L. (1998) Effects of the Kupffer cell inactivator gadolinium chloride on rat liver oxygen uptake and content of mitochondrial cytochromes. FEBS Lett. 426, 263-265.

Huettner, J., Stack, E. \& Wilding, T. (1998) Antagonism of neuronal kainate receptors by lanthanum and gadolinium. Neuropharmacology 37, 1239-1247.

Kim, S., Cho, J., Chung, Y., Ahn, E., Lee, K. \& Han, Y. (1998) Suppression of xenobiotic-metabolizing enzyme expression in rats by acriflavine, a protein kinase $\mathrm{C}$ inhibitor. Effects on epoxide hydrolase, glutathione $S$-transferases, and cytochromes P450. Drug. Metab. Dispos. 26, 66-72.

Klein, A., Zhadkewich, M., Margolick, J., Winkelstein, J. \& Bulkley, G. (1994) Quantitative discrimination of hepaticreticulo-endothelial clearance and phagocytic killing. J. Leukocyte Biol. 55, 248-252.

Kumamoto, E. \& Murata, Y. (1996) Lack of correlation between the molecular size and efficacy of lanthanides for potentiating $\mathrm{GABA}_{\mathrm{A}}$ currents in rat septal cholinergic neurons in culture. Brain. Res. 723, 235-237.

Ma, J. \& Narahashi, T. (1993) Enhancement of gamma-aminobutyric acid-activated chloride channel currents by lanthanides in rat dorsal root ganglion neurons. J. Neurosci. 13, 4872-4879.

Ma, J., Reuveny, E. \& Narahashi, T. (1994) Terbium modulation of single gamma-aminobutyric acid-activated chloride channels in rat dorsal root ganglion neurons. J. Neurosci. 14, $3835-3841$. 
Michael, S., Pumford, N., Mayeux, P., Niesman, M. \& Hinson, J. (1999) Pretreatment of mice with macrophage inactivators decreases acetaminophen hepatotoxicity and the formation of reactive oxygen and nitrogen species. Hepatology 30, 186-195.

Mlinar, B. \& Enyeart, J. (1993) Block of current through T-type calcium channels by trivalent metal cations and nickel in neural rat and human cells. J. Physiol. Lond. 469, 639-652.

Nakamura, Y., Tsumura, Y., Shibata, T. \& Ito, Y. (1997) Differences in behavior among the chlorides of seven rare earth elements administered intravenously to rats. Fundam. Appl. Toxicol. 37, 106-116.

Narahashi, T., Ma, J., Arakawa, O., Reuveny, E. \& Nakahiro, M. (1994) GABA receptor-channel complex as a target site of mercury, copper, zinc and lanthanides. Cell. Mol. Neurobiol. 14, 599-621.

Neyrinck, A., Eeckhoudt, S., Meunier, C., Pamfer, S., Taper, H., Verbeeck, R. \& Delzenne, N. (1999) Modulation of paracetamol metabolism by Kupffer cells: A study on rat liver slices. Life Sci. 65, 2851-2859.

Olynyk, J., Yeoh, G., Ramm, G., Clarke, S., Hall, P., Britton, R., Bacon, B. \& Tracy, T. (1998) Gadolinium chloride suppresses hepatic oval cell proliferation in rats biliary obstruction. Am. J. Pathol. 152, 347-352.

Pairon, J., Roos, F., Sebastien, P., Chamak, B., Abd-Alsamad, I., Bernaudin, J., Bignon, J. \& Brochard, P. (1995) Biopersistence of cerium in the human respiratory tract and ultrastructural findings. Am. J. Ind. Med. 27, 349-358.

Przywara, D., Bhave, S., Bhave, A., Chowdhury, P., Wakade, T. \& Wakade, A. (1992) Activation of $\mathrm{K}^{+}$channels by lanthanum contributes to the block of neurotransmitter release in chick and rat sympathetic neurons. J. Membr. Biol. 125, $155-162$.

Rai, R., Yang, S., McClain, C., Karp, C., Klein, A. \& Diehl, M. (1996) Kupffer cell depletion by gadolinium chloride enhances liver regeneration after partial hepatectomy in rats. Am. J. Physiol. 270, G909-G-918.

Roland, C., Naziruddin, B., Mohanakumar, T. \& Flye, M. (1999) Gadolinium blocks rat Kupffer cell calcium channels: Relevance to calcium-dependent prostaglandin E2 synthesis and septic mortality. Hepatology 29, 756- 765.

Rüttinger, D., Vollmar, B., Wanner, G. \& Messmer, K. (1996) In vivo assessment of hepatic alterations following gadolinium chloride-induced Kupffer cell blockade. J. Hepatol. 25, 960967.

RIC News Publ. Rare Earth Information Centre (1984-1995) Energy and Mineral Sources Institute. Iowa State University, Ames.

Spencer, A., Wilson, S., Batchelor, J., Reid, A., Rees, J. \& Harpur, E. (1997) Gadolinium chloride toxicity in the rat. Toxicol. Pathol. 25, $245-255$.

Tsien, R., Lipscombe, D., Madison, D., Bley, K. \& Fox, A. (1988) Multiple types of neuronal calcium channels and their selective modulation. Trends Neurosci. 11, 431-438.

Vaccari, A., Saba, P., Mocci, I. \& Ruiu, S. (1999) Lanthanides stimulate $(3 \mathrm{H})$ tyramine binding in the rat striatum. Neurosci. Lett. 261, 49-52.

Van der Laarse, W., Van Noort, P., Simonides, W., Digenbach, P., Lee de Groot, M. \& Van Hardeveld, C. (1995) Histochemistry of sarcoplasmic reticulum Ca-ATPase using dysprosium as capturing agent. Histochem. J. 27, $702-174$.

Wadkins, T., Benz, J. \& Briner, W. (1998) The effect of lanthanum administration during neural tube formation on the emergence of swimming behavior. Metal Ions Biol. Med. 5, 168-171.

Yokoyama, H., Fukuda, M., Okamura, Y., Mizukami, T., Ohgo, H., Kamegaya, Y., Kato, S. \& Ishii, H. (1999) Superoxide anion release into the hepatic sinusoid after an acute ethanol challenge and its attenuation by Kupffer cell depletion. Alcohol Clin. Exp. Res. 23, 71S$75 \mathrm{~S}$. 